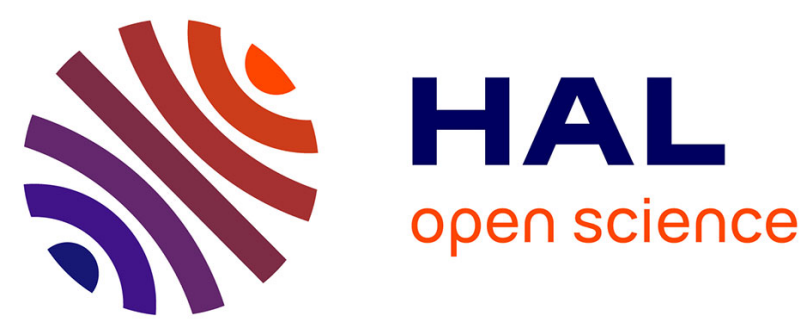

\title{
STEADY-STATE AND TIME-RESOLVED EXCITONIC OPTICAL NONLINEARITIES IN MBE-GROWN ZnSe
}

S. Park, B. Fluegel, R. Morgan, M. Joffre, S. Koch, Jérôme Sokoloff, N.

Peyghambarian, J. Potts, H. Cheng

\section{To cite this version:}

S. Park, B. Fluegel, R. Morgan, M. Joffre, S. Koch, et al.. STEADY-STATE AND TIME-RESOLVED EXCITONIC OPTICAL NONLINEARITIES IN MBE-GROWN ZnSe. Journal de Physique Colloques, 1988, 49 (C2), pp.C2-185-C2-187. 10.1051/jphyscol:1988243 . jpa-00227660

\section{HAL Id: jpa-00227660 https://hal.science/jpa-00227660}

Submitted on 1 Jan 1988

HAL is a multi-disciplinary open access archive for the deposit and dissemination of scientific research documents, whether they are published or not. The documents may come from teaching and research institutions in France or abroad, or from public or private research centers.
L'archive ouverte pluridisciplinaire HAL, est destinée au dépôt et à la diffusion de documents scientifiques de niveau recherche, publiés ou non, émanant des établissements d'enseignement et de recherche français ou étrangers, des laboratoires publics ou privés. 


\title{
STEADY-STATE AND TIME-RESOLVED EXCITONIC OPTICAL NONLINEARITIES IN
} MBE-GROWN ZnSe

\author{
S.H. PARK, B. FLUEGEL, R.A. MORGAN, M. JOFFRE* , S.W. KOCH, \\ J.P. SOKOLOFF, N. PEYGHAMBARIAN, J.E. POTTS ${ }^{*}$ and H. CHENG* \\ optical sciences Center, University of Arizona, Tucson, \\ AZ 85721, U.S.A. \\ * ENSTA, Ecole Polytechnique, F-91128 Palaiseau Cedex, France \\ ** 3M Center, 3M Company, 201-1N-35, st. Paul, MN 55144, U.S.A.
}

\begin{abstract}
Excitonic optical nonlinearities are time resolved in MBE-grown ZnSe thin films. The nonlinear index is comparable to $\mathrm{GaAs}$ and the recovery time is less than $100 \mathrm{ps}$.
\end{abstract}

\section{Introduction}

$\mathrm{ZnSe}$ is an interesting material for optical switching and computing applications. Thermal nonlinearities in polycrystalline $\mathrm{ZnS}$ and $\mathrm{ZnSe}$ have been employed extensively in the past for these applications., ${ }^{1,2}$ However, these switches have been slow and inefficient due to the thermal nature of the nonlinearity. We report large optical nonlinearities of electronic origin and their fast response time. The magnitude and dynamics of this excitonic effect are measured at various temperatures. These ZnSe films were grown by molecular beam epitaxy (MBE) on (100) GaAs substrates. The samples studied were $0.23,0.55$, and $0.68 \mu \mathrm{m}$ thick. The substrates were removed by chemical etching.

\section{Steady-State Excitonic Optical Nonlinearities in ZnSe}

In the first of two experiments, we measured the magnitude of this nonlinearilty using a standard pumpprobe technique. The broad-band probe and single-wavelength pump beam were of $\cong 3$ ns full width at halfmaximum (FWHM). Both pump and probe were synchronously generated by the same nitrogen laser. The pump beam was fixed at $435 \mathrm{~nm}$ directly generating an electron-hole plasma. We measured the absorption coefficient as afunction of probe wavelength for various pump intensities.

Figure la shows the experimental absorption spectra for the $0.55 \mu \mathrm{m}$ sample at $150 \mathrm{~K}$. The spectrum labeled 0 . which is taken in the absence of the pump beam, exhibits a pronounced exciton peak near $450 \mathrm{~nm}$.
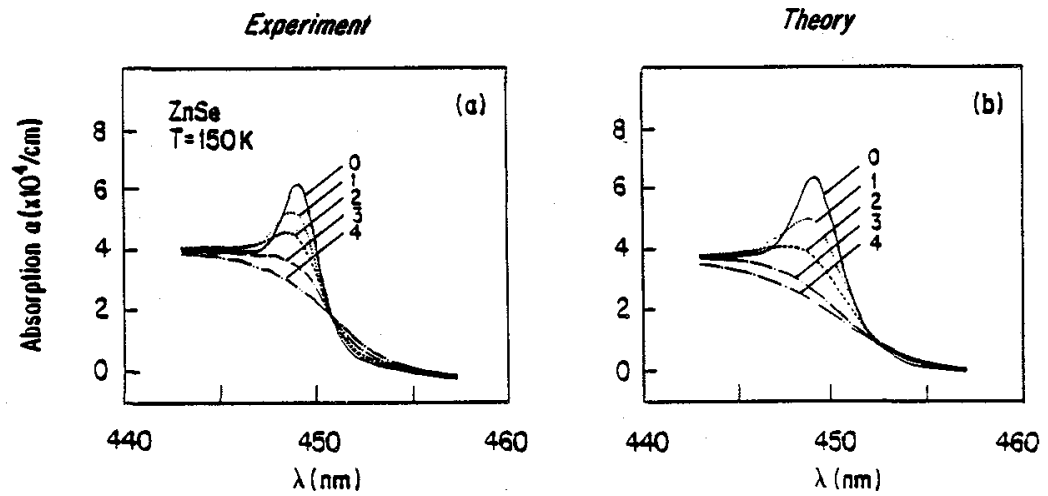

Fig. 1. (a) Experimental absorption spectra for a $0.55 \mu \mathrm{m} \mathrm{ZnSe}$ thin film at $\mathrm{T}=150 \mathrm{~K}: 0$ ) linear (no pump), 1) $2.5 \mathrm{~kW} / \mathrm{cm}^{2}$, 2) $9 \mathrm{~kW} / \mathrm{cm}^{2}$, 3) $23 \mathrm{~kW} / \mathrm{cm}^{2}$, 4) $46.5 \mathrm{~kW} / \mathrm{cm}^{2}$. (b) Calculated absorption spectra for different electron-hole pair densities : 0) $1 \times 10^{15} \mathrm{~cm}^{3}$, 1) $5 \times 10^{16} \mathrm{~cm}^{3}$, 2) $1 \times 10^{17} \mathrm{~cm}^{3}$, 3) $2 \times 10^{17} \mathrm{~cm}^{3}$, 4) $3 \times 10^{17} \mathrm{~cm}^{3}$ 
In the presence of the pump pulse, one observes a reduction of the exciton oscillator strength and a small broadening on either side of exciton. At higher pump intensities the exciton gradually disappears. This is due to the screening of the Coulorab potential by the pump-injected carriers. Similar measurements were repeated at room temperature as seen in Fig. 1b. Note, the magnitude of the nonlinear changes are comparable to those of bulk GaAs. ${ }^{5}$

The results were analyzed using a recently published plasma theory. This is a partly phenomenological scheme based on an extension of linear response theory with material paramenters that depend on the density of the e-h plasma. This gives an expression for the nonlinear absorption spectra which takes into account screening of the Coulomb interaction, band filling, bandgap reduction, and density dependent broadening of resonances. The theoretical absorption spectra are in good agreement with the results shown in Fig. $1 \mathrm{~b}$. The theory indicates that at room temperature the main contributions to the nonlinearities are exciton screening and density dependent broadening. At $150 \mathrm{~K}$, screening of the exciton is the most significant mechanism. ${ }^{5}$ It has to be emphasized that in contrast to previous results on $\mathrm{ZnSe}$, thermal effects do not play a role in the observed spectra.

\section{Time-Resolved Excitonic Optical Nonlinearities in ZnSe}

In the second set of experiments we measured the dymanics of the excitonic nonlinearities using time-resolved pump-probe spectroscopy. Free carriers were created by pumping above the ZnSe bandedge using a $310-\mathrm{nm}$ pump. The $\cong 100-f s$ pump pulse was obtained by frequency doubling the output from an amplified CPM dye laser. The change in transmission $(\Delta T)$ at a single wavelength was monitored by phase-sensitive detection of a continuum probe. The wavelength was tuned to the peak of the exciton and $\Delta T$ was recorded as a function of delay between pump and probe.

The exciton recovery time was investigated as a function of sample thickness, temperature. and pump intensity. The dependence on sample thickness at room temperature is shown in Fig. 2 . The recovery time ( $\tau$ ) was faster for the thinner samples. It ranged from $110 \mathrm{ps}$ for the $0.68 \mu \mathrm{m}$ sample to $40 \mathrm{ps}$ for the $0.23 \mu \mathrm{m}$ sample. This probably results from enhanced surface recombination. $\tau$ was also seen to decrease as the temperature decreased. It decreased from $90 \mathrm{ps}$ at room temperature to $50 \mathrm{ps}$ at $150 \mathrm{~K}$, for the $0.55-\mu \mathrm{m}$ thick sample. We tentatively attribute this to the increased exciton oscillator strength at lower temperatures which leads to a shorter lifetime. Further investigations are in progress.

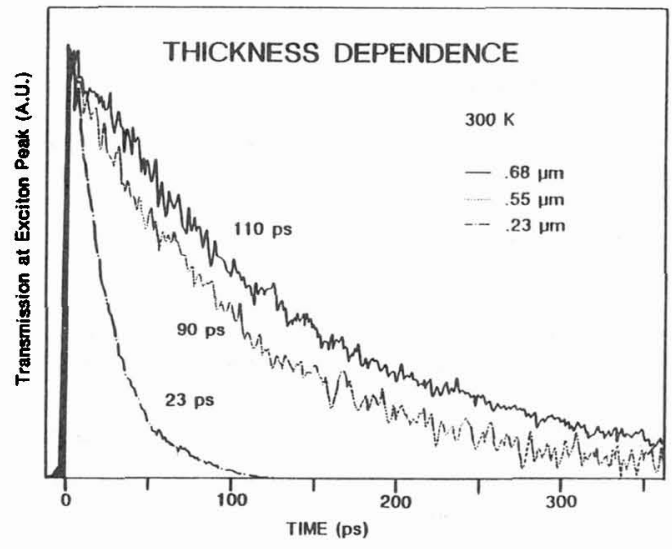

Fig. 2. Transmission at the exciton peak as a function of pump-probe delay for various thickness ZnSe thin films at room temperature.

\section{Acknowledgement}

We acknowledge support from NSF, SDIO/ONR, JSOP, OCC, RADC/DARPA and ONR/DARPA and a NATO travel grant.

\section{References}

1. G. Olbright, N. Peyghambarian, H.M. Gibbs, A. Macleod and F. VanMilligen, Appl. Phys. Lett. 45, 1031 (1984). 
2. S.D. Smith, J.G.H. Mathew, M.R. Taghizadeh, A.C. Walker, B.S. Wherrett and A. Hendry, Opt. Commun. 51, 357 (1984).

3. J.E. Potts, H. Cheng, S.K. Mohapatra and T.L. Smith, J. Appl. Phys. 61, 333 (1987).

4. L.A. Kolodziejski, R.L. Gunshor, N. Otsuka, S. Datta, W.M. Becker and A.V. Nurmikko, IEEE Jour. of Quant. Elect. QE-22, 1666 (1986).

5. N. Peyghambarian, S.H. Park, S.W. Koch, A. Jeffery, J.E. Potts, and H. Cheng, Appl. Phys. Lett. 52, 18 (1988). 